\title{
Introduction to the special issue on "Sharing economy and on-demand service business models"
}

\author{
Alanah Mitchell ${ }^{1}$ - Troy J. Strader ${ }^{1}$
}

Published online: 4 July 2018

(c) Springer-Verlag GmbH Germany, part of Springer Nature 2018

The sharing economy and on-demand services provide a link between organizations and/or individuals with excess capacity and the consumers who need the service. Some of the most popular examples include Lyft and Uber (transportation sharing), Airbnb (housing sharing), and Wework (office sharing). There has been dramatic growth in the sharing economy and on-demand services over the past few years, but there is a limited amount of research investigating the range of behavioral, strategic and technical issues that explain the success, failure, and impact these services will have on existing industries and the overall economy. The goal of this Information Systems and e-Business Management (ISeB) special issue is to present some of the research and current trends in relation to the sharing economy and on-demand service business models. The articles in this special issue utilize a variety of methodologies to highlight some of the different aspects of the on-demand services environment.

The special issue begins with a paper entitled, "Leveraging Social Media to Gain Insights into service delivery: a study on Airbnb" by Moritz von Hoffen, Marvin Hagge, Jan Hendrik Betzing and Friedrich Chasin. This paper begins with a background on the phenomenon of the sharing economy. Following this introduction, the authors present a software toolkit for collecting and filtering data related to the sharing economy and social media reviews and comments. The example of Airbnb is used to illustrate how the toolkit can work for identifying both positive and negative viewpoints from both reviews and tweets.

Alanah Mitchell

alanah.mitchell@drake.edu

Troy J. Strader

troy.strader@drake.edu

1 Department of Information Management and Business Analytics, College of Business and Public Administration, Drake University, Des Moines, IA, USA 
The second paper is "Carsharing Business Models in Germany: Characteristics, Success and Future Prospects" by Karla Münzel, Wouter Boon, Koen Frenken and Taneli Vaskelainen. This work attempts to classify the different types of car-sharing business models based on a German car-sharing database as well as compare the characteristics, successes, and challenges of each category. While this research is primarily exploratory, it does conclude with future predictions and research ideas for the car-sharing industry.

The third paper is, "Peer-to-peer Sharing and Collaborative Consumption Platforms: A Taxonomy and a Reproducible Analysis" by Friedrich Chasin, Moritz von Hoffen, Marcus Cramer and Martin Matzner. The authors of this paper prepare and evaluate a taxonomy for classifying Peer-to-Peer Sharing and Collaborative Consumption businesses such as Lyft, Uber, and Airbnb. The authors also present the taxonomy implications and possibilities for future research and exploration.

This special issue concludes with a paper entitled, "Providing Software as a Service: A Design Decision(s) Model" by Abhijit Dutt, Hemant Jain, and Sanjeev Kumar. The authors of this research present their work in the area of the sharing economy and on-demand service business models by specifically focusing on Software as a Service (SaaS). In this paper, the authors present a design decision model for SaaS providers that includes modularity of software architecture and architectural performance of the software along with attributes of user preference, user demand, and service price. The authors use mathematical modeling to study this phenomenon.

Taken together, the four papers in this special issue present a broad overview of the various areas related to the sharing economy and on demand business models. In closing, we would like to thank Professor Michael J. Shaw, Information Systems and e-Business Management (ISeB) Editor-in-Chief for his support of this special issue. We are also grateful to the authors for their valuable research contributions and the reviewers for their insightful and constructive feedback during the review process.

\section{About the guest editors}

Dr. Alanah Mitchell is an Associate Professor of Information Systems in the Department of Information Management and Business Analytics in the College of Business and Public Administration at Drake University. Her Ph.D. is in Information Technology from the University of Nebraska at Omaha. Professor Mitchell's research focuses on the design, implementation, and use of information and communication technologies for collaboration, specifically in global virtual teams. She has published in such journals as Journal of the Association for Information Systems, Communications of the Association for Information Systems, DATA BASE, International Journal of e-Collaboration, and American Journal of Business as well as others. She served as the President for the Association of Information Systems (AIS) Special Interest Group on IT Project Management (ITProjMgmt) from 2013 to 2016 and was a Program Co-Chair for AMCIS 2016 in San Diego.

Dr. Troy J. Strader is the Aliber Distinguished Professor of Information Systems in the Drake University College of Business and Public Administration. Dr. Strader 
received his Ph.D. in Business Administration (Information Systems) from the University of Illinois at Urbana-Champaign in 1997. His research interests include electronic markets, information technology ethics, digital product management, online consumer behavior, and the impact of the Internet and e-business on initial public offerings. Dr. Strader has published in the Journal of the Association for Information Systems, the European Journal of Information Systems, the Journal of Information Technology, Decision Support Systems, the International Journal of E-Commerce, and other academic and practitioner journals and books. He has edited three books, Digital Product Management, Technology and Practice: Interdisciplinary Perspectives, the Handbook on Electronic Commerce, and Mobile Commerce: Technology: Theory and Applications. His work experience is in software development and information systems analysis. 